DOI 10.18699/SBB-2020-43

\title{
Кластеризация возрастных трендов экспрессии генов РВМС
}

Алексеев А.А.

физический факультет МГУ имени М.В. Ломоносова, Москва, Россия

e-mail: alekseev@physics.msu.ru

Ключевые слова: старение, mRNA, тренды, скользящее среднее, кластеризация, РBMC

Введение: В настоящее время существует множество теорий старения человека, при этом для проверки этих теорий и построения системно-биологических моделей старения человека не хватает исходных данных в виде трендов, то есть изменения средних по популяции значений в омиксных данных [1]. В ряде недавних работ получены тренды по концентрации белков [2] и метаболитов [3] в крови, однако в настоящее время не развиты подходы для получения трендов экспрессии генов для клеток человека. Эта задача осложнена отсутствием в открытых источниках значимого объема данных экспрессии мРНК по различным тканям человека, а также межиндивидуальной и межполовой вариабельностью в этих данных. Как мы ожидаем, получение трендов экспрессии позволит сразу приобрести значительный материал для изучения изменений в сигнальных и метаболических путях при старении человека. Эта надежда подтолкнула нас к разработке подхода, позволяющего получить тренды экспрессии для РВМС человека по нескольким датасетам, а также метод кластеризации этих трендов.

Meтоды и результаты: Мы воспользовались открытыми данными из базы GEO: 4 датасета для PBMC человека GSE75511, GSE30483, GSE47353, GSE68759 и опорный датасет GSE65907. Изучены гены, которые пересекаются по всем датасетам (11145 генов). Для образцов в каждом датасете указан пол и возраст. Подгонка к распределению экспрессии генов опорного датасета осуществлялась по 10 и 90\% квантилям, функция оптимизации optim языка R, оптимизировались пары параметров линейной функции преобразования. В результате для каждого гена получены несколько «объединенных» наборов точек (отдельно по каждому полу). Далее, по разработанному нами алгоритму скользящего среднего для каждого гена была была получена серия трендов, после усреднения которых найден итоговый тред. Полученные тренды были скластеризованы по группам с помощью корреляции и последующего выделения кластеров в графе (с помощью функций библиотеки iGraph в R).

Bblвод: Разработан метод получения возрастных трендов экспрессии генов, и кластеров трендов для PBMC человека, в том числе для генов, связанных с NAD+ и NADPH, которые интересны в контексте изучения старения.

\section{Список литературы}

3. Ahadi S. et al. Personal aging markers and ageotypes revealed by deep longitudinal profiling. Nat Med. 26, 83-90 (2020). https://doi.org/10.1038/s41591-019-0719-5.

4. Lehallier B. et al. Undulating changes in human plasma proteome profiles across the lifespan. Nat Med. 25, 1843-1850 (2019). https://doi.org/10.1038/s41591-019-0673-2.

5. Bunning BJ et al. Global metabolic profiling to model biological processes of aging in twins. Aging Cell. 19, e13073 (2020). https://doi.org/10.1111/acel.13073. 